J. Lake Sci. (湖泊科学) , 2015, 27(5): 983-990

DOI $10.18307 / 2015.0526$

(C) 2015 by Journal of Lake Sciences

\title{
基于多指标分析的博斯腾湖表层沉积物有机碳来源“
}

\author{
于志同 ${ }^{1,2,3}$, 王秀君 ${ }^{1}$, 赵成义 $^{1 * *}$, 兰海燕 $^{2}$ \\ (1: 中国科学院新疆生态与地理研究所荒漠与绿洲生态国家重点实验室,乌鲁木齐 830011) \\ $(2$ : 新疆大学资源与环境科学学院, 乌鲁木齐 830046) \\ (3: 中国科学院大学,北京 100049)
}

摘 要: 通过有机碳稳定同位素 $\left(\delta^{13} \mathrm{C}_{\text {org }}\right)$ 、有机碳、氮含量及其比值 $(\mathrm{C}: \mathrm{N})$ 的测定, 结合已有的正构烷烃空间分布特征数 据, 对新疆博斯腾湖表层沉积物的有机碳来源进行综合研究. 结果表明: 博斯腾湖表层沉积物 $\delta^{13} \mathrm{C}_{\mathrm{org}}$ 值在 $-26.7 \%$ $-24.1 \%$ 之间波动, 变幅较小; $\mathrm{C}: \mathrm{N}$ 的波动范围为 $4.8 \sim 8.5$, 平均值约为 7.4; 正构烷烃的碳数分布范围为 $\mathrm{nC} 13 \sim \mathrm{nC} 35$, 所有采样点样品的主峰碳以 $\mathrm{nC} 17$ 和 $\mathrm{nC} 23$ 为主. 参考博斯腾湖文献调查资料, 基于 $\delta^{13} \mathrm{C}_{\mathrm{org}}$ 值、 $\mathrm{C}: \mathrm{N}$ 及正构烷烃等指标的 空间分布状况,发现博斯腾湖表层沉积物中的有机碳主要来自湖泊内部浮游生物的残体; 而不同湖区沉积物有机碳的 内、外源贡献比例不同,其中陆源碎屑、挺水植物、沉水植物的贡献空间差异较大. 博斯腾湖有机碳来源的空间差异主要 表现在湖泊东部近岸水域表层沉积物有机碳主要为外源贡献, 中心湖泊东部和西部浅水区表层沉积物有机碳由外源和 内源共同贡献,而其余大部分水域表层沉积物有机碳则主要为内源贡献.

关键词: 博斯腾湖;有机碳来源; $\mathrm{C}: \mathrm{N}$; 有机碳稳定同位素;正构烷烃

\section{Source characterization of organic carbon using elemental, isotopic and n-alkanes prox- ies in surface sediment from Lake Bosten, Xinjiang}

\author{
YU Zhitong ${ }^{1,2,3}$, WANG Xiujun ${ }^{1}$, ZHAO Chengyi ${ }^{1}$ \& LAN Haiyan ${ }^{2}$ \\ (1: State Key Laboratory of Desert and Oasis Ecology, Xinjiang Institute of Ecology and Geography, Chinese Academy of Sci- \\ ences, Urumqi 830011, P. R. China) \\ ( 2: College of Resources and Environmental Sciences, Xinjiang University, Urumqi 830046, P. R. China) \\ ( 3: University of Chinese Academy of Sciences, Beijing 100049, P. R. China)
}

\begin{abstract}
Lake sediment is an important carbon reservoir thus plays a role in the terrestrial carbon cycle. However, little is known on the dynamics and sources of organic carbon in the lake surface sediment from northwest China. In this paper, we applied element analyses, isotopic and n-alkanes approach to study the sources of organic carbon in the Lake Bosten, the largest inland lake in Xinjiang. We found that there was some spatial variability in $\mathrm{C}: \mathrm{N}(4.8-8.5)$ and stable carbon isotopic composition in $\delta^{13} \mathrm{C}_{\text {org }}$ values ( $-26.7 \%$ to $-24.1 \%$ ). The carbon numbers of n-alkanes ranged from C13 to C35, with the dominating compounds C17 and C23 in most samples. Further analyses showed that organic carbon in the surface sediments was generally from the autochthonous sources. There existed a relatively large spatial variability in contributions from different sources. According to the lake survey data and the spatial distribution characteristic of $\mathrm{C}: \mathrm{N}, \delta^{13} \mathrm{C}_{\text {org }}$ and $\mathrm{n}$-alkanes, we estimated that the organic carbon sources in the east near-shore lake area, central-east section and western shallow lake area, and the other lake parts were mainly attributable to allochthonous, autochthonous plus allochthonous, and autochthonous sources, respectively.
\end{abstract}

Keywords: Lake Bosten; sources of organic carbon; $\mathrm{C}: \mathrm{N} ; \delta^{13} \mathrm{C}_{\text {org }}$; n-alkanes

* 中国科学院战略性先导科技碳专项 (XDA05020202)、中德合作项目 (GZ867) 和国家自然科学基金项目 (41403072) 联合资助. 2015-06-30 收稿;2015-07-21 收修改稿. 于志同(1985 ) , 男,博士研究生; E-mail : yztgeo@ms.xjb.ac.cn.

** 通信作者;E-mail:zcy@ ms. xjb. ac. cn. 
湖泊作为内陆水体的重要组成部分, 与陆地生态系统发生着强烈的物质和能量交换, 具有较高的生产 力 $^{[1]}$. 同时, 湖泊是流域内物质的主要汇集场所, 其沉积速率较高, 是研究全球环境变化的重要载体 ${ }^{[2]}$. 尽 管湖泊水体占地球表面积较小, 越来越多的研究表明湖泊是一个不容忽视的碳汇 ${ }^{[3-4]}$, 其生物地球化学强度 分别是陆地和海洋生态系统的 33 和 115 倍, 而且有机碳埋藏速率甚至大于海洋 ${ }^{[5]}$.

世界各地湖泊, 如北美 ${ }^{[6]}$ 、西欧 ${ }^{[7-8]}$ 、东亚 ${ }^{[9-10]}$ 及其他湖区 ${ }^{[11]}$ 的研究表明, 湖泊表层沉积物中有机碳的含 量空间差异很大. 影响湖泊表层沉积物中有机碳含量高低的因素很多, 包括水体初级生产力、陆源有机质输 人、沉积特征及微生物降解的速率等 ${ }^{[2-13]}$. 其中, 有机碳内、外源的贡献直接影响着其含量在表层沉积物中 的空间分布 ${ }^{[4,7]}$, 可能是湖泊生产力和湖泊形态等不同造成的 ${ }^{[14]}$. 一般来说, 生产力较高的湖泊, 其沉积物 中有机碳主要来自于湖泊本身, 而生产力低的湖泊, 则主要来源于水体外的有机碳 ${ }^{[6]}$; 小而浅的湖泊, 其有 机碳可能主要来源于湖岸带, 而大而深的湖泊, 特别是峡湾湖泊, 则主要来源于湖泊水体内浮游生物的增 殖 ${ }^{[14-16]}$. 目前, 区分沉积物中有机碳来源的方法主要有同位素法 $\left(\delta^{14} \mathrm{C} \& \delta^{13} \mathrm{C}\right)$ 、元素比值法 $(\mathrm{C}: \mathrm{N})$ 及生物标 志物法 (正构烷烃、脂肪酸) 等 ${ }^{[10-11,17]}$, 并且被越来越多的国内外研究者应用于湖泊物源示踪及生物地球化 学过程机理的研究.

博斯腾湖作为新疆地区最大的湖泊, 是干旱区湖泊的典型代表. 前人对该湖碳循环的研究较少, 多数是 利用沉积物中的有机碳、无机碳含量进行古环境、古气候方面的反演与重建 ${ }^{[18-21]}$, 仅张成君等 ${ }^{[22]}$ 探讨过该湖 表层沉积物无机碳 $\mathrm{C} 、 \mathrm{O}$ 同位素的组成及影响因素, 指出湖水滞留时间和水-气 $\mathrm{CO}_{2}$ 交换量影响无机碳同位 素的组成, 而对无机碳的来源、空间分布及影响因素未作深人探讨. 近年来, 对博斯腾湖水体有机碳和表层 沉积物无机碳的系统研究发现, 博斯腾湖水体的有机碳时空变化明显且受外源影响较大 ${ }^{[23]}$, 表层沉积物无 机碳主要为湖泊自生碳酸盐, 其空间分布受开都河、黄水沟等人湖河水和局部水动力条件的影响 ${ }^{[24]}$. 在人 类活动的强烈干扰下,博斯腾湖的水位和水质变化较大 ${ }^{[25-27]}$, 尤其是人湖径流量的改变可能对湖泊有机碳 来源及分布有着直接或间接的影响. 然而, 目前对于博斯腾湖表层沉积物有机碳的来源及沉积机制的研究 相对较少. 因此, 深人研究博斯腾湖沉积物中有机碳的来源及空间差异, 不仅可以补充并完善该湖碳循环的 研究内容, 而且能深化对湖泊系统内部有机碳、无机碳累积转化的认识, 为干旱区湖泊碳循环研究提供新的 科学依据.

\section{1 材料与方法}

\section{1 研究区域概况}

博斯腾湖 $\left(41^{\circ} 32^{\prime} \sim 42^{\circ} 14^{\prime} \mathrm{N}, 86^{\circ} 19^{\prime} \sim 87^{\circ} 26^{\prime} \mathrm{E}\right.$ ) 地处新疆天山南麓, 是焉耆盆地的最低点 (图 1). 湖面海拔 $1048 \mathrm{~m}$, 流域面积约为 $55600 \mathrm{~km}^{2}$, 湖区东西长 $55 \mathrm{~km}$, 南北宽 $25 \mathrm{~km}$, 总面积 $1646 \mathrm{~km}^{2}$ ( 2002 年水位最高时数 据). 1950s 以来, 在气候和人类活动的影响下 ${ }^{[28-29]}$, 博斯腾湖水位多次急剧变化, 波动幅度在 $1044 \sim 1049 \mathrm{~m}$ 之间.

湖区深居欧亚大陆中心, 属温带大陆性干旱气候, 多年平均气温 $8.4^{\circ} \mathrm{C}$, 多年平均降水量 $94.7 \mathrm{~mm}$, 年均 蒸发量 $1880 \mathrm{~mm}$. 博斯腾湖主要由开都河来水补给, 是唯一常年有水人湖的河流, 开都河山口处多年平均径 流量为 $34.12 \times 10^{8} \mathrm{~m}^{3}$, 约占人湖径流量的 $95 \%{ }^{[30]}$; 同时流人博斯腾湖的河流还有黄水沟、清水河、乌拉斯 台河、曲惠河和乌什塔拉河等, 均为季节性补给. 博斯腾湖具有开都河来水的水资源调控、孔雀河流域农田 灌溉、工业及城乡生活用水、流域生态环境保护和向塔里木河中下游紧急调水等多种功能, 在塔里木河流域 乃至新疆生态环境与社会经济中处于特殊地位 ${ }^{[31]}$.

\section{2 样品采集与分析}

1.2.1 样品采集 博斯腾湖分为大小两个湖区, 大湖的西南端分布着一连串的浅水小湖, 盛长芦苇, 称为小 湖苇区, 本文主要以大湖区为研究对象. 根据博斯腾湖的水体形态设置了 13 个采样点 (图 1), 使用重力采 样器对表层沉积物进行采集, 现场将顶部 $2 \mathrm{~cm}$ 样品封装于自封袋内, 并冷藏于保温箱内带回实验室在 $-4^{\circ} \mathrm{C}$ 保存.

1.2 .2 元素分析 将真空冷冻干燥后的样品研磨至 80 目左右的粉末状, 用锡囊封装好直接送人 EA 3000 (Euro Vector, Italy) 型元素分析仪进行总氮 ( TN) 的测定. 取适量冻干后样品放人标准银杯中, 滴加 2 滴 
$5 \%$ 的 $\mathrm{HCl}$, 置于电热板上 $60^{\circ} \mathrm{C}$ 烘 $2 \mathrm{~h}$, 之后再滴加 $1 \sim 2$ 滴, 调至 $40^{\circ} \mathrm{C}$, 直至将样品蒸干后, 用锡囊封装好送 人 EA 3000 (Euro Vector, Italy) 型元素分析仪, 进行总有机碳( TOC) 的测定 ${ }^{[32]}$.

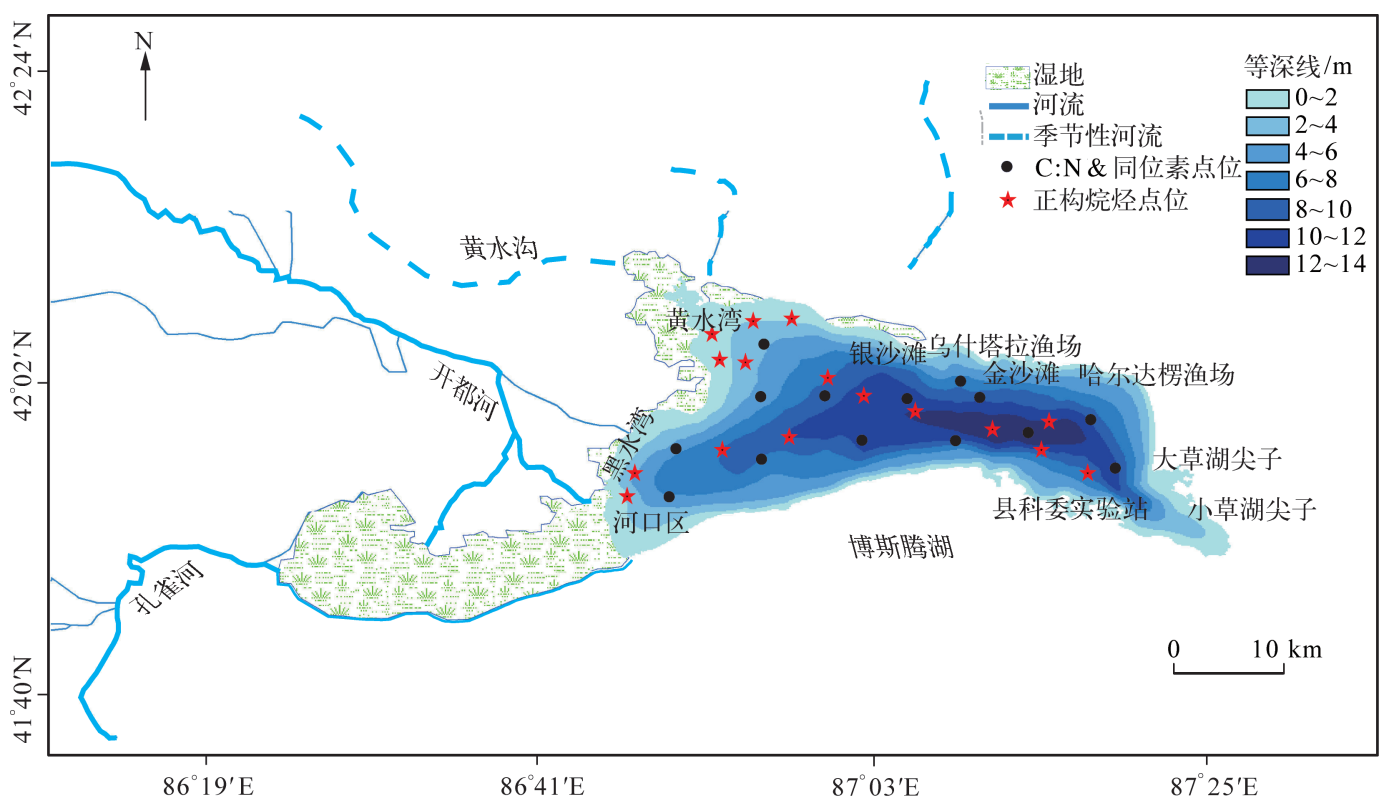

图 1 博斯腾湖及采样点位置

Fig. 1 Location of Lake Bosten and sampling sites

1.2 .3 有机碳稳定同位素分析 取一定量的冻干研磨后的沉积物样品,加人 $10 \%$ 的稀盐酸去除样品中碳酸 盐后,用去离子水反复清洗至中性烘干, 研磨至 80 目以下. 称取一定量样品用锡囊封装好, 经过 Flash EA1112 元素分析仪然烧后将气体送人 Thermo Delta ${ }^{\text {Plus }}$ Advantage 同位素质谱仪测定 $\delta^{13} \mathrm{C}$. 有机碳稳定同位 素 $\left(\delta^{13} \mathrm{C}_{\text {org }}\right)$ 的结果以 VPDB 为标准,测量误差为 $\pm 0.1 \%$.

\section{3 数据处理与成图}

正构烷烃的数据引自文献 [33], 采样点设置如图 1 所示,本研究采用克里格空间差值法对其进行数据 处理,进而得出正构烷烃 4 个不同参数的空间分布状况. 其中, $\sum n \mathrm{nC} 23^{-} / \sum \mathrm{nC} 25^{+}$为短链与长链正构烷烃之 比; CPI 为正构烷烃碳优势指数; 奇偶优势指数 $\mathrm{OEP}=(\mathrm{nC} 23+6 \mathrm{nC} 25+\mathrm{nC} 27) /(4 \mathrm{nC} 24+4 \mathrm{nC} 26)$; 参数 Paq $=$ $(n C 23+n C 25) /(n C 23+n C 25+n C 29+n C 31)$, 用来区分沉水/浮游植物相对于挺水植物与陆生高等植 物物源贡献. 其余数据均来自本课题组采样分析, 用 Excel 2010 进行数据预处理, 博斯腾湖及采样点 位置、等深线图采用 ArcGIS 10.0 \& CorelDRAW X3 软件绘制, 空间分布图由 Surfer 9.0 \& CorelDRAW $\mathrm{X} 3$ 软件绘制.

\section{2 结果}

\section{$2.1 \delta^{13} \mathrm{C}_{\text {org }}$ 的空间分布特征}

博斯腾湖表层沉积物 $\delta^{13} \mathrm{C}_{\mathrm{org}}$ 的变化范围为 $-26.7 \% 0 \sim-24.1 \%$, 变幅较小,最为偏负的样品出现在 $41.9 \sim 42.0^{\circ} \mathrm{N}$ 和 $86.9 \sim 87.0^{\circ} \mathrm{E}$ 之间, 而最为偏正的样品出现在靠近西北黄水沟人湖口处. 总体上, $\delta^{13} \mathrm{C}_{\mathrm{org}}$ 值在东部和中心湖区要比西北和西南湖区偏负 (图 2a).

\section{2. $2 \mathrm{C}: \mathrm{N}$ 的空间分布特征}

博斯腾湖表层沉积物 $\mathrm{C}: \mathrm{N}$ 的变化范围为 $4.8 \sim 8.5$, 平均值约为 7.4. $\mathrm{C}: \mathrm{N}$ 整体上表现为中部湖区比其 他湖区高, 最大值出现在西部中心深水区 (偏南部), 而最低值出现在西北黄水湾湖区. $\mathrm{C}: \mathrm{N}$ 与 $\delta^{13} \mathrm{C}_{\mathrm{org}}$ 大致呈 
现出相反的空间分布格局 (图 2b).
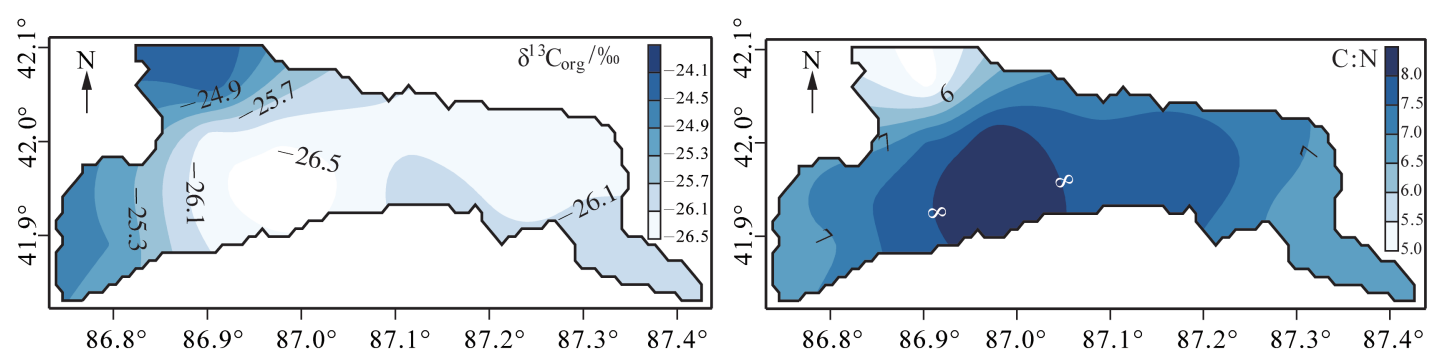

图 2 博斯腾湖表层沉积物 $\delta^{13} \mathrm{C}_{\text {org }}$ (a) 和 $\mathrm{C}: \mathrm{N}(\mathrm{b})$ 的空间分布

Fig. 2 Spatial distribution of $\delta^{13} \mathrm{C}_{\text {org }}$ (a) and $\mathrm{C}: \mathrm{N}$ ratio(b) of TOC in the surface sediment of Lake Bosten

\section{3 正构烷烃的空间分布特征}

博斯腾湖表层沉积物正构烷烃的碳数分布范围为 $\mathrm{nC13} \sim \mathrm{nC} 35$, 各点位主峰碳以 $\mathrm{nC} 17$ 和 $\mathrm{nC} 23$ 为主. $\sum \mathrm{nC}^{2} 3^{-} / \sum \mathrm{nC} 25^{+} \lim _{x \rightarrow \infty}$ 空间差异较为明显, 西北水域数值明显高于西南河口区和东部湖区, 最高值出现在 $42.0 \sim 42.1^{\circ} \mathrm{N}$ 和 $86.9 \sim 87.0^{\circ} \mathrm{E}$ 之间 (图 4a). CPI 空间上呈现出 3 个高值区, 即西北黄水湾东部 (偏北岸)、 中心湖区和西南河口区, 而东部湖区数值明显低于其他水域 (图 4b). OEP 的空间分布与 CPI 相似, 中心湖 区数值最高 $(5.1 \sim 7.2)$, 而东部湖区最低 $(1.3 \sim 3.9)$. Paq 最低值出现在湖泊西部近岸水域 $(0.1 \sim 0.3)$, 而最高值出现在中心湖区偏西部深水区 $(0.62 \sim 0.64)$, 整体上与 CPI 分布相反 (图 $4 d$ ).
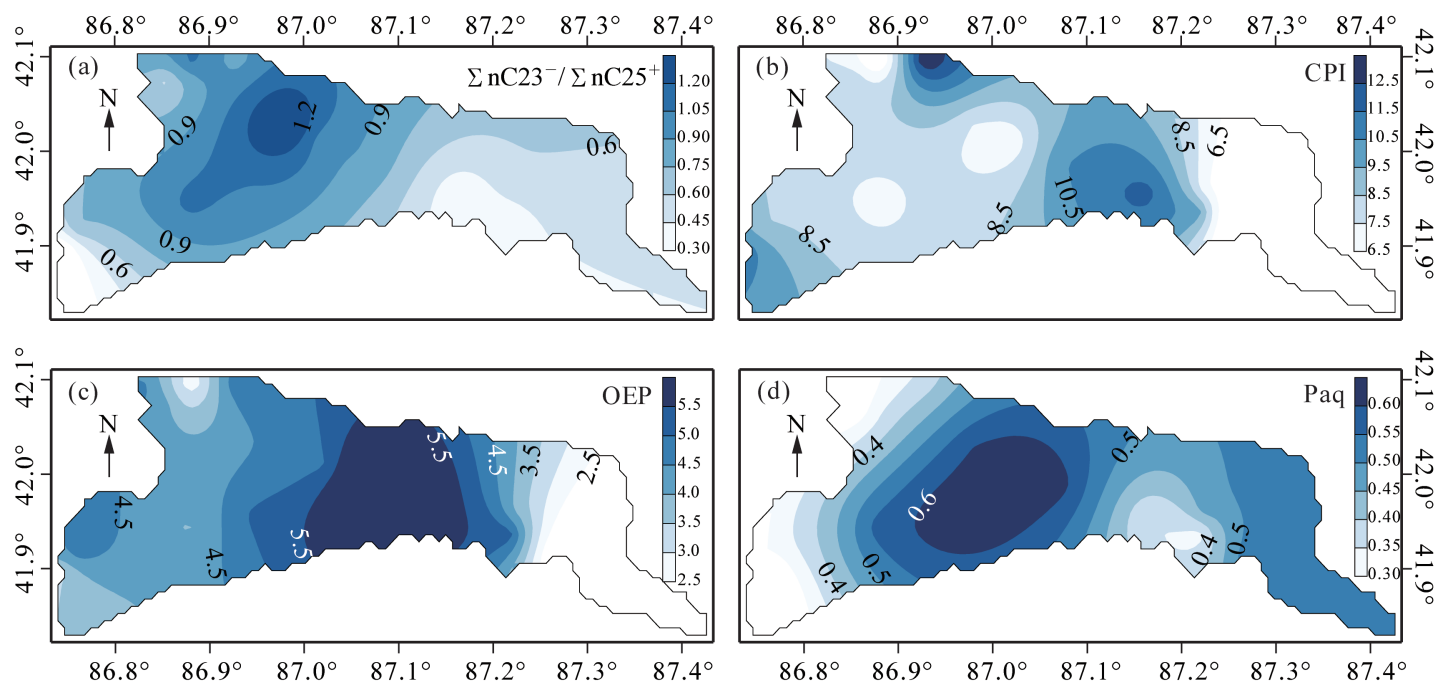

图 3 博斯腾湖表层沉积物正构烷烃的空间分布

Fig. 3 Spatial distribution of n-alkanes in the surface sediment of Lake Bosten

\section{3 讨论与结论}

\section{1 基于多指标综合探讨博斯腾湖表层沉积物的有机碳来源}

湖泊沉积物有机碳或是内源 (产自湖中) 或是外源 (即从湖泊周围地区搬运到湖泊中), 其相对含量取 决于湖泊中生物产率和汇水区的特征 ${ }^{[34]}$. 目前, 一系列的技术方法已经被应用于湖泊沉积物有机碳来源的 
区分 ${ }^{[7,35-37] .}$

在生物化学过程中, ${ }^{12} \mathrm{C}$ 比 ${ }^{13} \mathrm{C}$ 更容易被利用,这样便引起了同位素的分馏. 不同环境下形成的有机物, 其母体利用碳的方法不同, 具有不同的 $\delta^{13} \mathrm{C}$ 特征值, 这就为利用同位素判断沉积物中有机碳的来源提供了 依据 ${ }^{[38-39]}$. 陆生植物按照光合作用类型可分为 $\mathrm{C}_{3}$ 植物、 $\mathrm{C}_{4}$ 植物和 $\mathrm{CAM}$ 植物. $\mathrm{C}_{3}$ 植物多适合冷湿气候环境, $\delta^{13} \mathrm{C}_{\text {org }}$ 的变化范围为 $-37 \%$ - 24\% ; $\mathrm{C}_{4}$ 植物适合暖干的气候环境, 其 $\delta^{13} \mathrm{C}_{\text {org }}$ 值为 $-19 \% 0 \sim-9 \%$; CAM 植物 的 $\delta^{13} \mathrm{C}_{\text {org }}$ 变化范围为 $-30 \% \sim-10 \%{ }^{[40]}$. 湖泊水生植物的 $\delta^{13} \mathrm{C}_{\text {org }}$ 范围很广, 为 $-50 \% 0 \sim-11 \%$, 其中挺水 植物与漂浮植物主要利用大气中的 $\mathrm{CO}_{2}$ 进行光合作用, $\delta^{13} \mathrm{C}_{\mathrm{org}}$ 与 $\mathrm{C}_{3}$ 植物相似; 而沉水植物的碳源主要是溶解 态的 $\mathrm{CO}_{2}$ 以及 $\mathrm{HCO}_{3}^{-}\left(\delta^{13} \mathrm{C}_{\text {org }}=1 \%\right)^{[41]}$. 博斯腾湖表层沉积物 $\delta^{13} \mathrm{C}_{\text {org }}$ 的平均值为 $-25.9 \%$, 变幅为 $-26.7 \%$ $-24.1 \%$, 数值与湖泊挺水植物、漂浮植物和陆生 $\mathrm{C}_{3}$ 植物的 $\delta^{13} \mathrm{C}_{\text {org }}$ 接近. 另外, 根据前期在博斯腾湖流域的 实地考察发现,博斯腾湖周围农作物较少且农作物每年的生长季不超过 6 个月,因此可以推断荒漠灌丛植 被是陆生高等植物的主要贡献者. 依据最近焉耆盆地的研究 ${ }^{[42]}$, 发现湖周荒漠灌丛植物和表层土壤的 $\delta^{13}$ $\mathrm{C}_{\text {org }}$ 值分别为 $-26.4 \%$ 和 $-23.6 \%$. 因此, 单纯依据单一的 $\delta^{13} \mathrm{C}_{\mathrm{org}}$ 值无法准确判断出表层沉积物有机碳的 来源.

由于不同物源的同位素特征值有交叠的部分 ${ }^{[4344]}$, 因此,还需借助有机物的 $\mathrm{C}: \mathrm{N}$ 比值来推测其主要来 源. 已有研究表明, 不同来源的有机质具有不同的 $\mathrm{C}: \mathrm{N}$ 比值范围: 湖泊浮游植物的 $\mathrm{C}: \mathrm{N}$ 比值是 $5 \sim$ $10^{[44-45]}$; 大多数细菌等微生物的 $\mathrm{C}: \mathrm{N}$ 比值在 $3 \sim 5$ 之间 ${ }^{[46]}$; 陆地植物具有较高的 $\mathrm{C}: \mathrm{N}$ 比值, 通常大于 $20^{[4445]}$; 而土壤有机质的 $\mathrm{C}: \mathrm{N}$ 比值范围为 $8 \sim 15^{[46]}$. 另外, 湖周荒漠灌丛植物和表层土壤的平均 $\mathrm{C}: \mathrm{N}$ 值 分别为 22.1 和 $10^{[42]}$. 博斯腾湖表层沉积物 $\mathrm{C}: \mathrm{N}$ 的变化范围为 $4.8 \sim 8.5$, 平均值约为 7.4, 大致可以推断 出该湖表层沉积物有机碳是以湖泊内源贡献为主.

随着有机化学分析中的色谱和色谱一质谱联用技术的发展,使得生物标志物被越来越多的国内外研究 者应用于湖泊物源示踪研究 ${ }^{[8,11,35]}$. 其中, 正构烷烃是湖泊沉积物中有机质的常见组分, 较难被微生物降 解, 主要来自不同生物的类脂化合物, 其碳数组成差异较大. 一般来说, 短链正构烷烃 $(\mathrm{nC} 13 \sim \mathrm{nC} 21)$ 主要来 源于光合作用的微生物和各种藻类, 中等碳链长度的正构烷烃 $(\mathrm{nC} 21 \sim \mathrm{nC} 25)$ 主要来自沉水植物和漂浮植 物, 而长链正构烷烃 $(\mathrm{nC} 25 \sim \mathrm{nC} 35)$ 主要源自陆生维管束高等植物和挺水植物 ${ }^{[37,47]}$. Meyers 的研究指出正 构烷烃奇碳数分布优势主要与有机质的来源有关, 细菌和藻类等微生物主峰碳为 C15 或 C17, 呈单峰型分 布 ${ }^{[48]}$; 苔藓植物、漂浮植物和沉水植物等水生植物多以 C21、C23、C25 合成正构烷烃 ${ }^{[49]}$; 而陆生高等植物和 挺水植物主峰碳为 C27、C29、C31, 奇偶优势明显且呈单峰型分布 ${ }^{[50]}$. 因此, 湖泊沉积物中以单峰型且低碳 数为主峰反映出有机碳主要来自低等菌藻类; 以单峰型、高碳数为主峰的正构烷烃主要由陆生高等植物或 挺水植物贡献; 而以双峰型碳数分布则表明有机碳是混合来源 ${ }^{[1-52]}$. 博斯腾湖表层沉积物正构烷烃的碳数 分布范围为 $\mathrm{nC13} \sim \mathrm{nC} 35$, 全湖主峰碳以 $\mathrm{nC} 17$ 和 $\mathrm{nC} 23$ 为主, 表明有机碳主要来自菌藻类、漂浮植物和沉水 植物等.

综上所述,博斯腾湖表层沉积物有机碳整体上以内源贡献为主, 主要来自湖泊水体浮游生物. Wünnemann 等 ${ }^{[53]}$ 发现博斯腾湖近百年来沉积物中存在大量的绿藻和硅藻等浮游植物残体, 这也印证了本 研究的结果.

\section{2 博斯腾湖表层沉积物有机碳内、外源贡献的空间差异性}

博斯腾湖中不同湖区沉积物有机碳的内、外源贡献比例不同, 而且空间差异较大. 正构烷烃 $\sum \mathrm{nC} 3^{-}$/ $\sum \mathrm{nC} 25^{+}$指标显示湖泊西部水域内源贡献明显高于外源, 而西南河口区、东部湖区 (偏南岸) 陆源组分比例 较高; $\operatorname{Paq}(<0.4)$ 显示在西部浅水沿岸带及中心东部湖区 (偏南岸) 陆源贡献及挺水植物贡献较大, 而中心 西部湖区则以浮游植物贡献为主, 东部湖区以沉水植物和浮游植物为主 (图 4). CPI 和 OEP 在东部湖区和 西北黄水沟水域数值较低, 说明上述区域有机质在沉积过程中存在一定的后期改造过程.

根据博斯腾湖文献调查资料 ${ }^{[54]}$ : 挺水植物以芦苇的生物量最大, 主要分布在黄水湾区和大湖西岸区; 而 水生植物分布最广的种类是金鱼藻 (Ceratophyllum demersum) , 其次是狐尾藻 (Myriophyllum) 、蕰草 (Potamogeton crispus)、眼子菜 (Potamogeton) 、大茨藻 (Najas marina) 等, 集中在河口区到黑水湾、黄水湾一带和乌 什塔拉渔场和县科委实验站附近的北部、东部浅水区域; 沿岸带 $(1 \sim 2 \mathrm{~m}$ 水深区 $)$ 和亚沿岸带 
(5 6 $\mathrm{m}$ 水深区) 也有沉水植物, 而大湖湖中深水区无沉水植物. 参考上述湖泊调查资料, 通过对 $\delta^{13} \mathrm{C}_{\mathrm{org}}$ 值、 $\mathrm{C}: \mathrm{N}$ 和正构烷烃空间分布特征的综合对比研究, 表明博斯腾湖湖泊主体水域表层沉积物有机碳主要为内源 贡献, 而东部近岸水域表层沉积物有机碳主要是为外源贡献, 中心湖泊东部和西部浅水区表层沉积物有机 碳由外源和内源共同贡献. 此外, 西北黄水湾水域由于接纳了流域内大量有机污染物, 湖泊水体已达到富营 养化水平, 导致西北湖区有机碳来源比较复杂.

总体上, 博斯腾湖表层沉积物中的有机碳主要来自湖泊内部浮游生物的残体, 而陆源碎屑、挺水植物和 沉水植物的贡献空间差异较大. 一些研究表明, 小而浅的湖泊有机碳外源贡献较大, 大而深的湖泊一般以内 源贡献为主, 有机碳主要来自水体的浮游生物 ${ }^{[14-16]}$. 博斯腾湖作为中国内陆最大的淡水湖, 表层沉积物中有 机碳以内源为主, 与世界很多面积较大的湖泊具有相似性. 这一现象在青藏高原湖区 ${ }^{[10,55]}$ 、长江流域 ${ }^{[56]}$ 和 东北平原湖区 ${ }^{[57]}$ 也较为常见. 而不同区域湖泊表层沉积物的有机碳空间分布格局具有较大差异性,这主要 与有机碳物源的供应、沉积速率的改变、氧气曝光时间的长短、微生物活动强弱等因素有关 ${ }^{[58-59]}$.

\section{4 参考文献}

[1 ] 王苏民, 窦鸿身. 中国湖泊志. 北京: 科学出版社, 1998.

[ 2 ] Cole JJ, Carpenter SR, Kitchell JF et al. Plumbing the global carbon cycle: integrating inland waters into the terrestrial carbon budget. Ecosystems, 2007, 10(1): 172-185.

[ 3 ] Downing JA, Cole JJ, Middelburg JJ et al. Sediment organic carbon burial in agriculturally eutrophic impoundments over the last century. Global Biogeochemical Cycles, 2008, 22(1): GB1018.

[ 4 ] Anderson NJ, D'Andrea W, Fritz SC. Holocene carbon burial by lakes in SW Greenland. Global Change Biology, 2009, $15(11)$ : 2590-2598.

[ 5 ] Downing JA. Plenary lecture global limnology : up-scaling aquatic services and processes to planet Earth. Verh Internat Verein Limnol, 2009, 30(8) : 1149-1166.

[6] Dean WE, Gorham E. Magnitude and significance of carbon burial in lakes, reservoirs, and peatlands. Geology, 1998, 26 : $535-538$.

[ 7 ] Bechtel A, Schubert CJ. A biogeochemical study of sediments from the eutrophic Lake Lugano and the oligotrophic Lake Brienz, Switzerland. Organic Geochemistry, 2009, 40(10) : 1100-1114.

[ 8 ] Woszczyk M, Bechtel A, Gratzer R et al. Composition and origin of organic matter in surface sediments of Lake Sarbsko: A highly eutrophic and shallow coastal lake (northern Poland). Organic Geochemistry, 2011, 42(9) : 1025-1038.

[ 9 ] Khim BK, Jung HM, Cheong D. Recent variations in sediment organic carbon content in Lake Soyang (Korea). Limnolo$g y, 2005,6(2): 139-139$.

[10] Wang Y, Zhu LP, Wang JB et al. The spatial distribution and sedimentary processes of organic matter in surface sediments of Nam Co, Central Tibetan Plateau. Chinese Science Bulletin, 2012, 57(36) : 4753-4764.

[11] Dunn RJ, Welsh DT, Teasdale PR et al. Investigating the distribution and sources of organic matter in surface sediment of Coombabah Lake (Australia) using elemental, isotopic and fatty acid biomarkers. Continental Shelf Research, 2008,28 (18) : 2535-2549.

[12] Burone L, Muniz P, Pires-Vanin A et al. Spatial distribution of organic matter in the surface sediments of Ubatuba Bay (Southeastern-Brazil). Anais da Academia Brasileira de Ciências, 2003, 75(1) : 77-80.

[13] Gireeshkumar TR, Deepulal PM, Chandramohanakumar N. Distribution and sources of sedimentary organic matter in a tropical estuary, south west coast of India (Cochin estuary) : A baseline study. Marine Pollution Bulletin, 2013, 66 (1/ $2)$ : 239-245.

[14] Barnes MA, Barnes WC. Organic compounds in lake sediments. In: Lerman A ed. Lakes. New York: Springer, 1978 : 127-152.

[15] Shanahan TM, McKay N, Overpeck JT et al. Spatial and temporal variability in sedimentological and geochemical properties of sediments from an anoxic crater lake in West Africa: Implications for paleoenvironmental reconstructions. Palaeogeography, Palaeoclimatology, Palaeoecology, 2013, 374: 96-109.

[16] Sifeddine A, Meyers PA, Cordeiro R et al. Delivery and deposition of organic matter in surface sediments of Lagoa do Caçó (Brazil). Journal of Paleolimnology, 2011, 45(3) : 385-396. 
[17] Cole JJ, Carpenter SR, Kitchell JF et al. Pathways of organic carbon utilization in small lakes: Results from a wholelake ${ }^{13} \mathrm{C}$ addition and coupled model. Limnology and Oceanography, 2002, 47(6) : 1664-1675.

[18 ] Zhang W, Zhang C. The responding of carbon isotopic compositions of the organic sediments to environmental change since Holocene in the Bosten Lake, Xinjiang, China. Geochimica et Cosmochimica Acta, 2010, 74(12) : A1214-A1214.

[19] Zhang C, Feng Z, Yang Q et al, Holocene environmental variations recorded by organic-related and carbonate-related proxies of the lacustrine sediments from Bosten Lake, northwestern China. Holocene, 2010, 20(3) : 363-373.

[20] 陈发虎, 黄小忠, 张家武等. 新疆博斯腾湖记录的亚洲内陆干旱区小冰期湿润气候研究. 中国科学: D 辑: 地球科 学, 2007, 37(1): 77-85.

[21] 任雅琴, 王彩红, 李瑞博等. 有机质饱和烃和 $\delta{ }^{13} \mathrm{C}_{\mathrm{org}}$ 记录的博斯腾湖早全新世晚期以来生态环境演变. 第四纪研 究, 2014, 34(2) : 425-433.

[22] Zhang C, Mischke S, Zheng M et al. Carbon and oxygen isotopic composition of surface-sediment carbonate in Bosten Lake (Xinjiang, China) and its controlling factor. Acta Geologica Sinica - English Edition, 2009, 83(2) : 386-395.

[23] 王秀君, 房传苓, 于志同等. 新疆博斯腾湖水体颗粒和溶解有机碳的季节变化及其来源初探. 湖泊科学, 2014, 26(4) : 552-558. DOI 10. 18307/2014.0409.

[24] 于志同, 王秀君, 赵成义等. 博斯腾湖表层沉积物无机碳及其稳定同位素空间异质性. 湖泊科学, 2015, 27 (2) : 250-257. DOI 10. 18307/2015. 0208.

[25] 王 杰, 王 俊, 申金玉. 新疆博斯腾湖人湖水量变化及其对湖水位的影响分析. 水资源与水工程学报, 2013, 24(4) : 199-202.

[26] 吴敬禄, 马 龙, 曾海鳌. 新疆博斯腾湖水质水量及其演化特征分析. 地理科学, 2013, 33(2) : 231-237.

[27］周洪华, 李卫红, 陈亚宁等. 博斯腾湖水盐动态变化 (1951-2011 年) 及对气候变化的响应. 湖泊科学, 2014,26 (1) : 55-65. DOI 10.18307/2014.0107.

[28] 高华中, 姚亦锋. 近 50 年来人类活动对博斯腾湖水位影响的量化研究. 地理科学, 2005, 25(3): 3305-3309.

[29] 刘丽梅, 赵景峰, 张建平等. 近 50a 博斯腾湖逐年水量收支估算与水平衡分析. 干旱区地理, 2013, 36 (1): $33-40$.

[30] Guo M, Wu W, Zhou X et al. Investigation of the dramatic changes in lake level of the Bosten Lake in northwestern China. Theoretical and Applied Climatology, 2015, 119(1/2) : 341-351.

[31] 夏 军, 左其亭, 邵民诚. 博斯腾湖水资源可持续利用:理论. 方法.实践. 北京: 科学出版社, 2003.

[32] Eksperiandova LP, Fedorov OI, Stepanenko NA. Estimation of metrological characteristics of the element analyzer EuroVector EA-3000 and its potential in the single-reactor CHNS mode. Microchemical Journal, 2011, 99(2) : 235-238.

[33] 欧文佳. 正构烷烃分布特征及稳定同位素组成在湖泊污染监测中的应用一一新疆博斯腾湖为例. 兰州: 兰州 大学, 2010 .

[34] 沈 吉, 薛 斌, 吴敬禄等. 湖泊沉积与环境演化. 北京: 科学出版社, 2010 .

[35] Fang J, Wu F, Xiong Y et al. Source characterization of sedimentary organic matter using molecular and stable carbon isotopic composition of $n$-alkanes and fatty acids in sediment core from Lake Dianchi, China. Science of The Total Environment, 2014, 473/474: 410-421.

[36] Hanson PC, Buffam I, Rusak JA et al. Quantifying lake allochthonous organic carbon budgets using a simple equilibrium model. Limnology and Oceanography, 2014, 59(1) : 167-181.

[37] Meyers PA, Ishiwatari R. Lacustrine organic geochemistry—an overview of indicators of organic matter sources and diagenesis in lake sediments. Organic Geochemistry, 1993, 20(7) : 867-900.

[38 ] Zigah PK, Minor EC, Werne JP et al. Radiocarbon and stable carbon isotopic insights into provenance and cycling of carbon in Lake Superior. Limnology and Oceanography, 2011, 56(3) : 867-886.

[39] Raymond PA, Bauer JE. Use of ${ }^{14} \mathrm{C}$ and ${ }^{13} \mathrm{C}$ natural abundances for evaluating riverine, estuarine, and coastal DOC and POC sources and cycling: a review and synthesis. Organic Geochemistry, 2001, 32(4) : 469-485.

[40] Smith BN, Epstein S. Two categories of ${ }^{13} \mathrm{C} /{ }^{12} \mathrm{C}$ ratios for higher plants. Plant Physiology, 1971, 47(3) : 380-384.

[41] Keeley JE, Sandquist D. Carbon: freshwater plants. Plant, Cell \& Environment, 1992, 15(9) : 1021-1035.

[42] 张 娟. 焉惹盆地土地利用变化对土壤有机质的影响 [学位论文].乌鲁木齐: 中国科学院新疆生态与地理研究 所,2013.

[43] Thornton SF, McManus J. Application of organic-carbon and nitrogen stable-isotope and $\mathrm{C} / \mathrm{N}$ ratios as source indicators of 
organic-matter provenance in estuarine systems - evidence from the tay estuary, scotland. Estuarine Coastal and Shelf Science, $1994, \mathbf{3 8}(3)$ : 219-233.

[44] Kendall C, Silva SR, Kelly VJ. Carbon and nitrogen isotopic compositions of particulate organic matter in four large river systems across the United States. Hydrological Processes, 2001, 15(7) : 1301-1346.

[45] Rostad CE, Leenheer JA, Daniel SR. Organic carbon and nitrogen content associated with colloids and suspended particulates from the Mississippi River and some of its tributaries. Environmental Science \& Technology, 1997, 31 (11): 3218-3225.

[46] Paul EA. Soil microbiology, ecology, and biochemistry. Oxford: Academic Press, 2007.

[47] Ficken K, Li B, Swain DL et al. An n-alkane proxy for the sedimentary input of submerged/floating freshwater aquatic macrophytes. Organic Geochemistry, 2000, 31(7) : 745-749.

[48] Meyers PA. Applications of organic geochemistry to paleolimnological reconstructions: a summary of examples from the Laurentian Great Lakes. Organic Geochemistry, 2003, 34(2) : 261-289.

[49] Xie S, Nott CJ, Avsejs LA et al. Palaeoclimate records in compound-specific $\delta \mathrm{D}$ values of a lipid biomarker in ombrotrophic peat. Organic Geochemistry, 2000, 31(10) : 1053-1057.

[50] Bourbonniere RA, Meyers PA. Sedimentary geolipid records of historical changes in the watersheds and productivities of Lakes Ontario and Erie. Limnology and Oceanography, 1996, 41(2) : 352-359.

[51] 杨明生, 张虎才, 邹长伟等. 鄱阳湖沉积物正构烷烃特征及其生物源. 福建师范大学学报：自然科学版, 2014 , $30(3): 111-118$.

[52] 胡 星, 朱立平, 汪 勇等. 青藏高原西南部湖泊沉积正构烷烃及其单体 $\delta \mathrm{D}$ 的气候意义. 科学通报, $2014, \mathbf{5 9}$ (19) : 1892-1903.

[53] Wünnemann B, Mischke S, Chen F. A Holocene sedimentary record from Bosten Lake, China. Palaeogeography, Palaeoclimatology, Palaeoecology, 2006, 234(2/3/4) : 223-238.

[54] 高 光, 汤祥明, 赛. 巴雅尔图. 博斯腾湖生态环境演化. 北京:科学出版社, 2013.

[55] Liu W, Li X, An Z et al. Total organic carbon isotopes: A novel proxy of lake level from Lake Qinghai in the Qinghai Tibet Plateau, China. Chemical Geology, 2013, 347: 153-160.

[56] Gui Z, Xue B, Yao S et al. Organic carbon burial in lake sediments in the middle and lower reaches of the Yangtze River Basin, China. Hydrobiologia, 2013, $\mathbf{7 1 0}(1)$ : 143-156.

[57] Wang L, Mackay AW, Leng MJ et al. Influence of the ratio of planktonic to benthic diatoms on lacustrine organic matter $\delta^{13} \mathrm{C}$ from Erlongwan maar lake, northeast China. Organic Geochemistry, 2013, 54 : 62-68.

[58 S Sobek S, Anderson NJ, Bernasconi SM et al. Low organic carbon burial efficiency in arctic lake sediments. Journal of Geophysical Research: Biogeosciences, 2014, 119(6) : 2014JG002612.

[59] Sobek S, Durisch-Kaiser E, Zurbrugg RW et al. Organic carbon burial efficiency in lake sediments controlled by oxygen exposure time and sediment source. Limnology and Oceanography, 2009, 54(6) : 2243. 